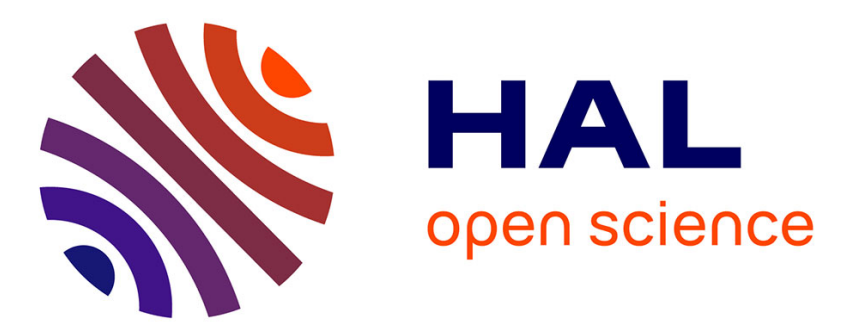

\title{
Emotional Disagreement. The role of semantic content in the expression of, and disagreement over, emotional values
}

Isidora Stojanovic

\section{- To cite this version:}

Isidora Stojanovic. Emotional Disagreement. The role of semantic content in the expression of, and disagreement over, emotional values. Dialogue: Canadian Philosophical Review / Revue canadienne de philosophie, 2012. ijn_00585302v2

\section{HAL Id: ijn_00585302 \\ https://hal.science/ijn_00585302v2}

Submitted on 27 Apr 2012

HAL is a multi-disciplinary open access archive for the deposit and dissemination of scientific research documents, whether they are published or not. The documents may come from teaching and research institutions in France or abroad, or from public or private research centers.
L'archive ouverte pluridisciplinaire HAL, est destinée au dépôt et à la diffusion de documents scientifiques de niveau recherche, publiés ou non, émanant des établissements d'enseignement et de recherche français ou étrangers, des laboratoires publics ou privés. 


\title{
Emotional disagreement
}

The role of semantic content in the expression of, and disagreement over, emotional values

Isidora Stojanovic, Institut Jean-Nicod - CNRS - ENS - EHESS

\begin{abstract}
When we describe an event as sad or happy, we attribute to it a certain emotional value. Attributions of emotional value depend essentially on an agent (and on his or her emotional responses); and yet, people readily disagree over such values. My aim in this paper is to explain what happens in the case of "emotional disagreement", and, more generally, to provide some insight into the semantics of value-attributions.

\section{Résumé}

Lorsque nous décrivons un évènement comme étant triste ou heureux, nous lui attribuons une certaine valeur émotive. Les attributions de valeur émotive dépendent toujours d'un agent (et de ses réponses et états émotifs); cependent, les gens sont fréquemment en désaccord sur de telles valeurs. Mon but dans le présent article sera d'expliquer le phénomène de "désaccord émotif", puis, plus généralement, d'éclairer certains aspects de la sémantique des attributions de valeurs.
\end{abstract}

\section{Introduction}

This paper aims to shed some light on the semantics of expressions of emotional value (such as "sad" and its compounds, like "it is sad that"). Such expressions bear striking similarities to predicates of personal taste (such as "delicious"); in particular, they also generate the so-called cases of faultless disagreement. In line with previous 
work, I will argue that genuine disagreement is never faultless. What happens is, rather, that at a first glance, we get both the intuition that there is disagreement and the intuition that each of the disagreeing parties is right, but further scrutiny makes one intuition prevail over the other, on a case to case basis. This, I argue, can be explained by taking the lexical meaning of expressions of emotion to underspecify the truth-conditional content of judgments involving such expressions (i.e. the conditions on what the world must be like for the judgment to come out true).

After developing and discussing this "underspecification hypothesis" in some detail, I will address the problem of residual disagreement, by which I mean the fact that even once the disagreeing parties clarify the intended interpretation of their value-judgments, it still remains unclear on which grounds they could possibly resolve their disagreement. I will suggest that, in such a case, underspecification is even more extreme, in that the concepts themselves associated with the values over which the disagreement bears are open-ended: whether the concept applies to a given instance or not is not yet settled by the previous uses of the concept. In this respect, residual disagreement can be viewed, or so I argue, as a kind of practical disagreement, where what is at issue is how to best shape concepts that are still under construction. 
Section I introduces the phenomenon of faultless disagreement, while sect. II provides a survey of the existing accounts. Sect. III lays down the underspecification hypothesis, which is then put to work in sect. IV to resolve the puzzle of faultless disagreement. The aim of section $\mathrm{V}$ is to position the account defended in this paper vis-à-vis other accounts, in particular, contextualist and relativist. Finally, sect. VI raises and addresses the problem of residual disagreement.

\section{Faultless disagreement over emotional value}

Consider the following case. You tell me that it's sad that Joshua's wife is leaving him after twenty years of marriage. I disagree. I reply that there is nothing sad about it, that he totally deserves it. We go on disagreeing, and we are both rational, so presumably either you or I must be wrong. At the same time, it seems that all that one could possibly require for a sentence of the form "it is sad that $\mathrm{p}^{\prime}$, as said by some person, to be true, is that this person finds it sad that $p$ should be the case. But of course, if you find it sad that Joshua's wife is leaving him, and I don't, then we are both speaking truly, so we can't be really disagreeing!

The phenomenon of faultless disagreement, as I understand it, stands simply for 
the fact that there are situations in which we have these two equally strong intuitions that go against each other:

\section{The disagreement intuition:}

The two parties genuinely disagree and contradict each other.

\section{The faultlessness intuition:}

Assuming that both parties are sincere, neither of them expresses a falsehood.

Faultless disagreement has received a great amount of interest in recent years, although the discussion has focused on two paradigm cases: predicates of personal taste, such as "tasty" and "fun", and epistemic modals, such as "might" or "must". ${ }^{1}$ In this paper, I shall discuss faultless disagreement as it arises with expressions of emotional value. My working example is the predicate "sad" and the corresponding sentential operator "it is sad that".

The problem to which the phenomenon of faultless disagreement gives rise can be regarded a set of independently plausible but mutually inconsistent assumptions, two of which are supported by the two intuitions pointed out earlier, and two of which come from more general theoretical assumptions. For the sake of clarity, let me first lay down the example:

1 About faultless disagreement involving taste predicates, see e.g. Kölbel 2002, Lasersohn 2005; involving epistemic modals, Egan et al. 2003; involving both, Stephenson 2007, MacFarlane 2012. 
(1) Abelard: It is sad that Joshua's wife is leaving him after 20 years of marriage.

(2) Eloise: No, that isn't sad at all.

The following four assumptions lead to contradiction.

a: $\quad$ Abelard in (1) and Eloise in (2) disagree and contradict each other.

b: Assuming that Abelard finds it sad, while Eloise doesn't, that Joshua's

wife is leaving him, neither (1) nor (2) express falsehoods.

c: (1) has a truth value, and so does (2).

$d$ : For any two utterances $u_{1}$ and $u_{2}$, the utterer of $u_{1}$ disagrees with the

utterer of $u_{2}$, and they contradict each other, only if:

if $u_{1}$ is true, then $u_{2}$ is false, and if $u_{1}$ is false, then $u_{2}$ is true.

As with any dilemma - or, in the present case, quadrilemma - the choice among the competing views will depend on the issue of which assumption can be given up most easily. In Stojanovic (2007), in relation to predicates of personal taste, I argued that one should reject either $a$ or $b$, but on a case to case basis. One of my goals in this paper will be to offer a solution along similar lines for the expressions of emotional value. ${ }^{2}$ In a nutshell, the idea is that a dialogue like (1)-(2) triggers, at a

2 Importantly, I will suggest that in certain cases, it is $c$ that should be rejected, the idea being that (1) and (2) do not yet have a truth value at the time of disagreement, but subsequently, they come 
first glance, both the disagreement and the faultlessness intuition, but that one of the two intuitions won't survive further scrutiny. Once we gather enough information on the context in which the dialogue takes place, and in particular, on the intentions of the two speakers and on the ways in which their dialogue might continue, we can resolve it either into a case of genuine disagreement, that is, of contradiction, or into a case of simultaneous truth (or, at least, non-falsehood) of the two utterances.

While the proposal just outlined was implicit in Stojanovic (2007), in this paper I shall formulate it more carefully, and present it as an empirical hypothesis, which I shall call the "Underspecification Hypothesis." The gist of this hypothesis is that the lexical meaning of predicates of taste like "tasty", but also of predicates of emotion like "sad" and compounds thereof, essentially underspecifies the complete truthconditional content of the claims and judgments that we make using such predicates. I will lay down and motivate this hypothesis in sections III and IV, while in sect. V, I will show that the underspecification hypothesis does not commit yet to any particular account of predicates of emotion, and can be handled in several ways. I will also put forward the sort of account that I favor, which can be labeled

to be either true or false (and when the one is true, the other is false, so that we get a difference in truth value retrospectively). This happens, I believe, in cases of residual disagreement, discussed in sect. VI, which I did not consider in Stojanovic (2007). 
"contextualist", and on which the move from the lexically encoded content to the complete truth-conditional content relies on pragmatic processes fairly similar to those involved in the resolution of covert pronouns. But before I move on to my own solution to the quadrilemma given by the inconsistency of $a, b, c$ and $d$, let me briefly discuss, in the next section, some other solutions that have been proposed.

\section{A quick glance at the existing accounts}

The family of views tagged with the labels like "absolutism", "invariantism", "objectivism" or "realism", find their way out of our quadrilemma by rejecting $b$. In other words, such a view will hold that the issue of whether an event such as Joshua's being left by his wife is sad or isn't can be decided without reference to any agent and his or her emotional response to the event at stake. And of course, if there is such an agent-independent answer to such issues, that explains how there can be disagreement and contradiction over sentences involving expressions of emotional value. The main problem that such views face is to account for the intuitive force behind $b$, and to be able to systematically predict truth values that match the ordinary speakers' intuitions. You might fear that my own view, which rejects sometimes $a$, sometimes $b$, on a case to case basis, is going to encounter the same 
problem. But, as we will see, the cases in which $b$ gets rejected are precisely those in which the intuition that there are objective or agent-independent grounds for deciding whether something is sad outweighs the intuition that the truth value of a given claim depends on some agent's emotional response.

It is sometimes believed that just as absolutist views reject $b$ once and for all, the family of views labeled as "contextualist" reject a once and for all. I believe that this characterization of contextualism is incorrect, even though there are probably views that hold indeed that a claim of the form 'it is sad that $p$ ' are always covertly about the speaker's emotions and emotional responses. Such views will, of course, have difficulties explaining why people disagree over matters of emotional value. They will also have difficulties accounting for the difference between 'it is sad that $p$ ' and 'I find it sad that $p$, since those two expressions end up being synonymous on such views.

In principle, our quadrilemma can also be resolved by giving up $c$ or $d$. There are two rather different types of proposal that give up c. One is the view (or the family of views) tagged by labels like "expressivism". As applied to expressions of emotion, the idea would be that, just as a mere facial expression of sadness does not have a truth value, and that weeps and cries are similarly truth valueless, it may be plausible to 
view speech acts made with sentences containing expressions of emotion as mere displays of emotion that are similarly devoid of truth value. Another view that also finds its ways out of the quadrilemma by rejecting $c$, but that does not reject the idea itself that a sentence containing an expression of emotion may, in principle, have a truth value, is what could be called the presuppositional approach, according to which the use of a predicate of taste (or, in our case, of emotion) introduces what has come to be called a "presupposition of commonality (see López de Sa 2008). The idea, as I understand it, is that a judgment of taste, or any other evaluative judgment of the same ilk, is felicitous, and can have a truth value, only in a context in which the standards of taste, or other evaluative criteria, are shared among the conversation participants. If there are no shared standards or criteria, the presupposition fails, and the sentence lacks a truth value as it would in any other case of presupposition failure.

As for rejecting $d$, that is the move made by certain "relativist" views, as in Kölbel 2002, Lasersohn 2005, as well as Richard 2008. ${ }^{3}$ Note that other relativist views (in particular, John MacFarlane's) are not willing to give up $d$ outright. I take it to be rather obvious why one would want $c$ and $d$ to be the last ones to go. For one thing,

3 I came to believe that Richard's view is somewhat more complex and should not be seen as a mere rejection of $d$. For discussion, see Stojanovic 2011. 
positing a split between sentences that behave in the same way - e.g. sentences that get embedded under truth-functional operators such as the negation, that occur as antecedents of the conditionals, and so on - and taking certain among them to be true or false and others to be simply deprived of truth value, is a move whose cost is very high, while the benefits are relatively low (for instance, expressivism will have a hard time to account for the fact that rational, linguistically competent speakers engage in disagreement over emotional value). For another, to say that there can be a "disagreement" even if both parties are simultaneously right is tantamount to redefining the term 'disagreement', and associating with it a concept that just isn't our ordinary concept of disagreement. In other words, there is nothing problematic to have a technical notion of disagreement that does not conform to $d$. But if this should constitute a viable way out of the problem, then we must be told how this technical notion relates to the ordinary, intuitive notion.

Let me, then, close this section by making an important concession, namely that I have surveyed the various options and tentative proposals only in rough moves, and that the difficulties that I have briefly pointed out are neither knockdown objections nor insuperable obstacles. Let me also emphasize that, to my knowledge, none among the accounts just discussed has been explicitly applied to expressions of 
emotions. But to the extent that faultless disagreement arises in a similar (if not exactly the same) way with predicates of personal taste, the accounts devised for these are straightforwardly applicable to predicates of emotion. At any rate, my goal in this paper is certainly not to argue that all the existing proposals fail and that mine is the only one that works. My goal is to lay out, clarify, and give credibility to a certain proposal - a task to which I now turn.

\section{A first stab at the underspecification hypothesis}

My proposal, in a nutshell, is that the question of whether a dialogue like the one illustrated in (1)-(2) is an instance of a genuine disagreement, or merely a dispute that arises from some form of misunderstanding, or, thirdly, merely an expression of the two parties' respective emotional responses, is a question that cannot be answered as it stands, without learning more about the context in which the dialogue takes place, and about the two parties' beliefs and communicative intentions. Furthermore, I hold that the reason why the answer can only be given once the context has been made specific enough is that the linguistic expressions involved in (1) and (2) lack meanings specific enough that would enable us to determine the conditions on what the world must be like for (1) or (2) to come out 
true. ${ }^{4}$ This idea is what lies behind the underspecification hypothesis, which I

propose to formulate as follows:

\section{The Underspecification Hypothesis:}

The lexical meanings of the expressions that occur in sentences such as (1) or (2), their syntax, and the semantic values of overt indexicals (such as personal and temporal pronouns), altogether underspecify the conditions on what the world must be like for an utterance of (1), or of (2), to be true.

Before discussing at greater length what the underspecification hypothesis amounts to, let me outline an intuitive understanding of the idea, albeit on a slightly different case. Imagine Abelard and Eloise in a furniture store buying a sofa, and consider this dialogue between them:

(3) Abelard: This sofa is very comfortable.

(4) Eloise: No, it is quite uncomfortable.

4 I would like to put emphasis on the idea that the meanings associated with the sentences in (1) and (2) are not specific enough to enable us to determine what the world needs to be like for (1) and (2) to be true. Note, however, that the notion of truth conditions can also be understood is a way that makes it possible to identify meaning with truth conditional content. We would then say, for example, that 'it is sad that $p$ is true at world $\mathrm{w}$, time $t$, and with respect to agent a, iff $p$ is sad from the viewpoint of a in $\mathrm{w}$ at $\mathrm{t}$. This gives us conditions not only on what the world needs to be like, but also on what the agent and the time need to be like, in order for an utterance of 'it is sad that $p$ ' to be true (with respect to the world, agent and time at stake). I have argued elsewhere that there is no reason not to view such conditions as "truth conditions"; see Stojanovic 2008: 22-23. 
The case of (3)-(4) displays the features of faultless disagreement, and can be used to generate the very same quadrilemma that we had with (1)-(2). Does this mean that de confortibus non est disputandum? Note though that by only modifying the example slightly, we can spot peculiar features of the predicate "comfortable". Thus imagine Abelard and Eloise in a shoe store, having just tried on (one after the other) the very same pair of shoes:

(5) Eloise: These shoes are very comfortable.

(6) Abelard: No, they are quite uncomfortable!

In the case of (5)-(6), there is no faultless disagreement. Rather, Abelard's claim is ambiguous between denying Eloise's claim - which would amount to denying that the shoes are comfortable to her - and claiming that the shoes are uncomfortableto him! In either case, Abelard's replique strikes us as bizarre. If the former, then there is disagreement, but an epistemically weird one, since what evidence could possibly allow Abelard to rationally question Eloise's judgment that concerns her own feeling of comfort? And if the latter, then the faultlessness intuition overthrows completely the disagreement intuition: of course a pair of shoes that are comfortable to Eloise need not be comfortable at all to Abelard! Note also that if (6) is thus 
interpreted, the negation marker "no" becomes rather infelicitous.

The upshot of this example is to shed light on the role of context in the interpretation of expressions such as "comfortable". In the context of shopping for a sofa, the issue of whether the sofa at stake is comfortable leaves ample room for disagreement, while in the context of shopping for a pair of shoes, the issue can be settled by determining whether the shoes at stake are comfortable to the person who shall be wearing them (and who, in this case, is the speaker). ${ }^{5}$

Before leaving matters of comfort and turning back to emotional matters, there is something else worth pointing out - just so that we can ignore it for the rest of the paper. Adjectives like "comfortable" are gradable adjectives, and their interpretation depends on the context insofar as it requires a specification of a comparison class, as well as of a scale and of a threshold within the given comparison class. To illustrate this form of context-dependence of adjectives like "comfortable", consider again a certain pair of shoes, and suppose that they are stiletto shoes. As a matter of rule,

5 Let me stress that I am not suggesting that whenever 'comfortable' occurs in application to 'shoes', it means 'comfortable to the speaker'. For, suppose that the following is said by Mr. Wang who is a shoemaker:

(1) All the shoes you find in this shop are comfortable.

It would be ridiculous to interpret Mr. Wang as saying that all those shoes are comfortable to him - if for nothing else, then because the shoes are of various sizes, and some won't even fit his feet. Rather, the most plausible interpretation would go along the following lines:

(2) For all $x$ and all $y$ : if $x$ is a shoe that you find in this shop, and if $y$ is appropriately related to $x$, then $\mathrm{x}$ is comfortable to $\mathrm{y}$. 
stilettos, with their slender, sharp-pointed heels, are rather uncomfortable. Now suppose that a friend of mine, whose feet are the same size as mine, needs to borrow shoes from me as we are about to go on a mountain hike. I tell her:

(7) These shoes are comfortable.

If I can equally well lend some flat-sole walking shoes, which would be much more comfortable than the stilettos, then what I say in (7) is false. On the other hand, if I utter (7) in the context of going to some fancy party, where the only alternatives are other stiletto shoes, then what I say in (7) may well be true (assuming that the shoes at stake are comfortable insofar as stiletto shoes go).

We should expect adjectives of emotional value to be subject to the same sort of context-dependence as other gradable adjectives. Thus it may be a sad thing that Abelard got a stomach flu during his holidays in the context of discussing the holidays of his colleagues who all had a wonderful time. On the other hand, if the relevant comparison class consists of events like Abelard's cousin being diagnosed with incurable cancer, his having been abused as a child, etc., then his getting a stomach flu will be hardly deemed a sad event at all. This being clarified, I shall ignore comparison-class sensitivity for the rest of the paper. 


\section{Underspecification and expressions of emotion}

Let us now see how the underspecification hypothesis connects with expressions of emotional value. The suggestion is that the sentence "It is sad that Joshua's wife is leaving him after 20 years of marriage" in (1), and, similarly, the negation of this sentence in (2), can be used in different contexts to express different things. I will only pay attention to the most obvious readings. ${ }^{6}$

On the strongest reading, what Abelard wants to and, presumably, does express (under appropriate circumstances) with (1), is what could be more explicitly expressed as follows:

(8) It is sad for everyone that Joshua's wife is leaving him after 20 years of marriage.

Of course, as with quantifier phrases in general, there may be a contextual restriction on the domain over which the quantifier "everyone" ranges. For instance, in the context at stake, the contextually restricted domain might include Joshua, his

6 Very little weight, if any, should be put on the idea that there will be "different things expressed" by different occurrences of the same sentence. In my previous work on assertion and what is said, I argued that even in the case of ordinary indexicals, we can maintain a notion of what is said (and, similarly, of what is expressed) that does not include any contextual elements over and above the lexically encoded material (see Stojanovic 2008: 121-130). Similarly, when, using linguists' jargon, I talk about the different "readings", that is just a façon de parler and shouldn't be given much weight either. 
wife, and all their family and friends (including Abelard and Eloise). Now, what happens when Eloise in (2) negates the sentence that Abelard asserted? Again, the underspecification hypothesis leaves several options. And again, we may want to give the expression of emotion the strong, "universal" reading, so that embedded under the negation operator, Eloise's claim could be more explicitly stated as follows:

(9) It is not the case that it is sad for everyone that Joshua's wife is leaving him after 20 years of marriage.

Note that on this reading, Abelard and Eloise contradict each other indeed - but only one of them will, in that case, be right. If we interpret (1) in a way that makes it equivalent to (8), and if we similarly interpret (2) as equivalent to (9), then, faced with our quadrilemma, we would reject $b$ (i.e. the assumption that neither party says something false).

It is important to note, however, that it is not enough to give the expression of emotion such a "universal" reading to secure contradiction. What is also required is that the two parties agree, implicitly or explicitly, on the domain over which the quantifier ranges (see Stojanovic 2012). Thus, if Abelard intends the domain to be restricted to Joshua and his friends and family, while Eloise intends a larger domain 
that also includes Joshua's wife (and the people on her side), then there is no more disagreement between Abelard and Eloise than there is between a mathematician who says "there is a number that has no predecessor" and another who "denies" this, when the former is talking of positive integers only, and the latter, of all integers, including negative ones.

Importantly, the underspecification hypothesis also allows for the possibility that (1) and (2) are both simultaneously true. As we have just seen, that may already happen when the two sentences' respective interpretations are as in (8) and (9), but the domains over which the quantifiers range are different. If the speakers are aware of this difference, then the dialogue in (1)-(2) will typically end there. But Abelard and Eloise could also go on "disagreeing", which is symptomatic of those cases in which the speakers take it for granted that they are talking of the same domain, whereas in fact, they are not.

I believe that "it is sad that" need not always receive a "universal" reading (or, for that matter, a weaker, generic reading) and that it can be given what we might call an "indexical" reading, on which "it is sad that" is roughly equivalent to "to me, it is sad that", and is more naturally expressed by "I find it sad that". In conversations in which it is mutually clear that this is the intended specification, the two parties' 
prima facie dispute typically comes to a halt: since each person is talking about what he or she finds sad, there is little point to deny or contradict what the other person is saying. In this sort of case, it is the assumption a of our quadrilemma that we would reject.

Before closing this section, let me point out that even when it is mutually clear that the intended interpretation is an indexical one, the two parties might still try to convince one another that their respective emotional responses are somehow "better" or more appropriate. To appreciate this point, consider some sad event (e.g. Abelard's cousin being diagnosed with incurable cancer) and suppose that someone tells you that she finds the event rather amusing. If the person is sincere, then it would be unreasonable of you to try to convince her that she told you something false: if she sincerely says that she finds it amusing, then it can only be true that she does find it amusing. However, there is a sense in which you may try to prove her to be wrong: the event at stake just isn't amusing, and those who find it amusing are wrong in finding it so. So even in cases in which assumption a gets rejected, there is something that looks like disagreement: the two parties strive to prove each other to be wrong (in the sense just discussed, but not in the sense of making contradictory claims) and may well appeal to arguments to show the other to be wrong. Disagreement, in such 
cases, seems to be disagreement over what one should find sad or amusing. This, in turn, may either be assimilated to the normative case (viz. on what one ought to consider sad or amusing), or to a kind of practical disagreement (viz. on what kind of behavior one had better adopt in given circumstances). What matters it that it is definitely not disagreement in the sense of contradiction, which is required to derive inconsistency from assumptions a to $d$, and is central to faultless disagreement. ${ }^{7}$

\section{Semantic underspecification and the contextualism- relativism debate}

It has been held (e.g. in Kölbel 2002, Lasersohn 2005) that the phenomenon of faultless disagreement requires abandoning our traditional semantic frameworks, and adopting a new framework: that of "relativist" semantics. In Stojanovic 2007, I argued that relativist semantics (or, more precisely, any framework along the lines of the one proposed in Lasersohn 2005) is nothing more than a notational variant of the more traditional "contextualist" semantics that does not posit any special

7 To draw what I hope is a helpful analogy, suppose that Abelard and Eloise are discussing the idea of whether to have an ice-cream after each has already had a dessert. Abelard's argument is that the ice-cream at stake is really delicious, while Eloise's argument is that they've already had dessert and will feel sick from eating too much. When Abelard finally says "Well, me, I'll have an icecream", and Eloise replies "Well, me, no, I won't have an ice-cream", we might say that they haven't quite resolved their disagreement - but we would not consider that to be a case of faultless disagreement. 
parameter in the circumstances of evaluation, but holds that there is an implicit argument, of the same type as the parameter at stake, associated with the predicate under consideration. For example, in relativist semantics, "delicious" is a one-place predicate, but sentences are evaluated for their truth value with respect to a "judge" parameter, whereas in contextualist semantics, 'delicious' is a two-place predicate one of whose argument is of type "judge". I have argued that from the standpoint of semantics alone, the distinction between a framework that posits such a judge parameter vs. one that associates a judge argument with any given predicate of taste is pretty much a distinction without a difference. For, given a sentence containing a predicate of personal taste (or, for that matter, an expression of emotional value), and given an assignment of values to the parameters deployed in the definitions of truth (including all the relevant contextual parameters), the contextualist and the relativist semantics, if suitably construed, will predict the same truth value. ${ }^{8}$ The upshot of this result, which is what matters for the purposes of the present

8 This result can be established using a familiar model-theoretic method of defining a bi-directional translation procedure between the two formal languages. In a nutshell, what one shows is that given a sentence of one of the two formal languages, a structure of interpretation, and an assignment of values to the relevant parameters, this sentence is true if and only if the translation of that sentence in the other formal language is true in a suitably related structure of interpretation for a suitably related assignment of values. For details, see Stojanovic 2007: 699703. 
discussion, is that it is difficult to see how there could be any purely semantic motivations for preferring relativism over contextualism (or for that matter, for preferring contextualism over relativism). It also follows that faultless disagreement, however we analyze it, cannot in and by itself motivate relativist semantics. For, from the point of view of semantics, relativism is just a notational variant of the traditional framework, so that if a phenomenon (whether of faultless disagreement or of something else) is to be considered as a motivation for a certain semantics, it can only be so if we make some extra-semantic assumptions (for instance, concerning computational complexity, the syntax-semantics interface, the semantics-pragmatics interface, and the like). In other words, whether relativist semantics is any better off than contextualist semantics with respect to faultless disagreement will crucially depend on how semantics relates, if at all, to the theory of disagreement.

My goal in the present section is to show that the account of faultless disagreement that I have outlined above, grounded upon the Underspecification hypothesis, works equally well with contextualist as with relativist semantics. Let me start with the sort of account that I favor, which is a kind of "contextualist" account. It holds that an expression such as "sad", in those uses in which it is ascribed to propositions, events, or other entities that are the causes of sadness (rather than 
being ascribed to agents who are experiencing sadness), comes with an implicit argument. This argument behaves like a variable that takes as its values agents or "experiencers", or rather, groups thereof. So, if you wish, the logical form of a sentence like "It is sad that $p$ " is, really, "It is sad to $x^{\prime} s$ that $p$ ", where the plural variable $x^{\prime} s$ can take as its value one or more individuals. Reconsider the dialogue between Abelard and Eloise, appropriately enriched with the experiencer argument:

(10) Abelard: It is sad [to x's] that Joshua's wife is leaving him after 20 years of marriage.

(11) Eloise: No, that isn't sad [to y's] at all.

Abelard and Eloise will be making claims that are negations of one another only to the extent that the values assigned to x's and y's are the same. ${ }^{9}$ Note, however, that the values needn't be exactly the same in order to be able to derive contradiction between (10) and (11). Suppose that the plural variable x's in (10) receives as its value the group that contains Joshua together with all of his family, friends and colleagues, while the variable y's in (11) receives as its value the subgroup that contains Joshua together with all of his family and friends but not all colleagues.

9 In (11), negation takes wide scope over the plural quantification: we read it as "It is not the case that to y's, p" and not "To y's, it is not the case that p". It remains, though, an interesting question whether (11) allows for a scope ambiguity - a question that I shall not try to address here. 
Then (10) and (11) are incompatible, so again, we might have disagreement, but crucially, not faultlessness: either Abelard or Eloise will be right, but not both. ${ }^{10}$

On the other hand, it is easy to see how we can have faultlessness without disagreement: consider a case in which Abelard in (10), in describing the event of Joshua's wife leaving him as a sad thing, speaks, as it were, from Joshua's perspective, while Eloise in (11), in rejecting the description of the event as a sad one, takes the perspective of Joshua's wife. Then the value that we would want to assign to x's in (10) is Joshua (or the singleton thereof), while the value assigned to y's in (11) is Joshua's wife. The truth of (10) will be then compatible with the truth of (11), even though (11) looks prima facie like the negation of (10). But crucially, in such a case, what initially looked like a disagreement between Abelard and Eloise will turn out not to be one, as the following possible continuation of the initial dialogue makes clear:

(12) Abelard: What I mean to be saying is that it is sad for Joshua that his wife is leaving him after 20 years of marriage.

(13) Eloise: I guess you're right about that, but for his wife, it isn't sad at all - quite

10 Although one might want to say that given that there is still some misunderstanding over the experiencer value, we fall short of genuine disagreement. We would then have a case in which the two parties take themselves to be disagreeing, and only one of them is actually right, but the disagreement is still somewhat spurious since it partly rests on a misunderstanding. 
to the contrary, it's fantastic that she's finally leaving him.

(14) Abelard: Yeah, I guess you're right about that.

Let me now show how relativist semantics can account for both scenarios. In saying that it's sad that Joshua's wife is leaving him after 20 years of marriage, the content (or proposition, if you prefer) that Abelard expresses is one that requires, in order to yield a truth value, not only a world of evaluation, but also a judge (or an experiencer, or a group thereof) at whom to be evaluated for truth; and similarly for the content that Eloise expresses. Hence to derive contradiction and get genuine disagreement between Abelard and Eloise, we ought to assume that the world and the judge(s) of evaluation are the same. Suppose that Abelard, in asserting (1), intends the asserted content to be evaluated for truth at the group including both Abelard and Eloise and their family, friends and colleagues, and that Eloise, too, intends that same group as the appropriate value for the judge parameter at which her claim is to be evaluated for truth. We then have a scenario of true disagreement, but I submit that (at least) one of them will be expressing falsehood. On the other hand, suppose that Abelard intends the content that he is asserting to be evaluated for truth at the group including Joshua and his friends, while Eloise takes it that the 
appropriate value is Joshua's wife and her friends. Then they may each be expressing truth (as evaluated with respect to these different values for the judge parameter), but since the intended values for the parameters of evaluation are not the same, I submit that their disagreement will not be any deeper than it would have been in (12)-(13)

\section{The Problem of Residual Disagreement}

The discussion from the previous section may lead one to think that the picture that I am working with goes more or less as follows. Expressions of emotional value, such as "sad" (as applied to events rather than agents), or "it is sad that", are semantically underspecified: in order to evaluate the claims containing such expressions for a truth value, one needs to specify, for instance, who the relevant experiencer(s) is (are), which can be done either by supplying a value to a hidden experiencer argument, or by specifying the experiencer value directly at the level of evaluation for a truth value. Either way, once the relevant value has been specified, there is a matter of fact whether the claim is true or false, and any disagreement over the claim ought to be resolvable on objective, factual grounds.

But, if that should be the picture, one might worry that even once the disagreeing 
parties have agreed upon some specific experiencer value, they may still go on disagreeing in a way that appears to be just as intractable as it was in the initial, underspecified case. For consider the following (albeit somewhat awkward) variant of Abelard and Eloise's dispute:

(15) Abelard: It is sad for Joshua, his wife and their kids and family, that she is leaving him after 20 years of marriage.

(16) Eloise: No, it isn't sad at all - it is actually great that she is finally leaving him.

One might insist that the disagreement between Abelard and Eloise in (15) and (16) is pretty much as faultless as it can get: if Abelard finds it sad - for Joshua, his wife, their kids and family - that she is leaving him, and if Eloise doesn't find that sad at all, then which objective, factual grounds could possibly allow us to decide whether Abelard rather than Eloise is right, or the other way round? But if this disagreement is one in which neither party is expressing falsehood, even though the values for the relevant arguments and parameters have all been duly specified, then don't we have a clear case of faultless disagreement after all? Or so the worry goes.

This is a legitimate worry that I would like to address in this final section. Let me start by pointing out that the picture of semantic underspecification that this worry 
presupposes is simpler than I take it to be. For I do not see any reason to assume that there must be a unique hidden argument associated with an evaluative expression such as a predicate of taste or emotion. To make the point clearer, consider the following example:

(17) Abelard: It is good for Joshua that he drives to work every day.

(18) Eloise: No, it isn't good for Joshua that he drives to work every day.

The dispute between Abelard and Eloise may well be a genuine disagreement, but it may also be a spurious disagreement that rests on a misunderstanding, because there is still some lingering underspecification as to the issue of deciding in which respect it is good for Joshua that he drives to work. If Abelard intends Joshua's own comfort to be the relevant respect, and grounds his judgment in the thought that it is much better for Joshua (i.e. Joshua's comfort) to drive than spend hours commuting, and yet if Eloise takes Joshua's health to be the relevant respect, and grounds her claim on the idea that if would have been better for Joshua (i.e. Joshua's health) to ride a bicycle to work rather than drive, then the apparent disagreement in (17)(18) is, again, a case of underspecification, and fails to constitute a genuine case of contradiction; witness the fact that the following "cumulative" judgment is a 
perfectly consistent one:

(19) Abelard/Eloise: It is good for Joshua in terms of his confort, but not in terms of his health, that he drives to work every day.

The upshot of this example is that if the underspecification with the evaluative term 'good' is such that there is not only one hidden argument (or a corresponding parameter in the circumstances of evaluation) that calls for an assignment of value for the whole statement to yield a truth value, but several such (viz. a person, object or group thereof for which/whom something is good, a respect in which it is good, and, as with any gradable adjective, a comparison class and a threshold...), then the same thing is likely to happen with other evaluative predicates, such as "sad". And, if so, then the objection according to which the intuition of faultlessness in (15)-(16) cannot result from underspecification no longer goes through. For, it could be that the reason why both Abelard in (15) and Eloise in (16) may be saying something true, despite the impression that they are contradicting each other, rests on the fact that the respect in which Abelard judges it to be a sad thing for Joshua, his wife and their family that she is leaving him after 20 years of marriage, is different from the respect in which Eloise judges it not to be a sad thing.

To be sure, the comparison with "good" shows that it is possible that "sad" involves 
more than one hidden argument (or equivalently, more than one corresponding parameter of evaluation), such as a respect in which something is sad, in addition to the person (or group of people) to whom it is sad; but it doesn't show that this is the case. If one wished to establish that there is indeed some sort of argument associated with "sad" that stands for the respect in which something is sad (and similarly for other emotional terms), one would need to engage in a thourough study of the lexical meaning of the predicate "sad" and other emotional vocabulary. That is a task for lexical semantics, which it would be unreasonable to try to carry out in a paper like the present one. Instead, what I would like to do it to tackle the worry outlined above in yet another manner. The question to which I now turn is the following. Can there be cases such that even after all the arguments and parameters of evaluation relevant to determining truth value have been identified and assigned their values, the disagreeing parties are still unable to resolve their disagreement on purely objective, factual grounds?

Suppose, for the sake of the argument, that Abelard and Eloise have reached a point at which there is no lingering underspecification whatsoever regarding the term "sad". For the sake of clarity, let their "final" disagreement be expressed in the following dialogue (where we should assume, in addition, that the class of events 
relative to which the sadness of Joshua's wife leaving him is being evaluated is the same for Abelard and Eloise, and that they place the threshold at the same level):

(20) Abelard: It is sad for Joshua, his wife and their kids and family, in every single respect, that she is leaving him after 20 years of marriage.

(21) Eloise: No, it isn't sad - in certain respects, it is actually great that she is finally leaving him.

How could one adjudicate the dispute in (20)-(21)? Perhaps one could mesure the emotional reactions of Joshua, his wife, and other members of the family, and see if, overall, the event of her leaving him has rendered them sad or not, and in which respect(s). Suppose that such a study has been done, and that Abelard and Eloise are equally aware of the results of the protagonists' emotional reactions. In other words, Abelard and Eloise are not talking past each other, they have endeavored to specify the meanings of the terms involved in their disagreement in every possible way, they are evaluating the sadness of the event at stake against the same comparison class, and, what is more, they have equally good knowledge of all the relevant facts! Yet couldn't it be that they are still unable to resolve their disagreement? Suppose that Abelard interprets the facts at stake (i.e. the various emotional reactions) as good 
evidence for the judgment that the event at stake is sad, and Eloise interprets the very same facts as supporting the judgment that it isn't sad. In other words, they are at a point where their dispute turns on a disagreement of what it takes for something to be a sad thing (or, if you prefer, to count as such). Doesn't it look, then, as if we had finally hit a case of genuine disagreement, yet one in which neither party is wrong?

The problem of residual disagreement, in sum, is that there seem to be cases in which the two parties disagree as to whether something is an instance of $F$ (for $F$ some predicate) because they disagree over what it takes for something to be $\mathrm{F}$, or to count as an F. And it is (arguably) a problem because in such cases, the disagreement appears to be genuine, the two parties are not victims of any misunderstanding, and nevertheless, there is no matter of fact as to which party is right (or if you wish, which party is more right than the other).

Drawing on ideas that have emerged from different horizons, ${ }^{11}$ I would like to propose that we consider such cases of residual disagreement as cases of practical disagreement of a special sort, namely, cases in which the parties disagree on how to best shape, or extend, a certain concept that is still under construction, so to speak.

To illustrate the idea (as I would like to construe it), consider the following dialogue: 11 See e.g. Ch. 6 of MacFarlane (2012), and, to some extent and with some caution, Ch. 4 of Richard (2008); for a different take, see Sosa (2010). 
(22) Abelard: Joshua has more than 20 publications.

(23) Eloise: No, he doesn't.

Suppose that Abelard and Eloise both know exactly what Joshua has written and published and where - in other words, they know all the relevant facts. Furthermore, let there be among Joshua's writings a number of online conference working papers, and suppose that when those are taken into account, he has more than 20 items, but not otherwise. Now, if Abelard counts such working papers as "publications" while Eloise doesn't, what will ground their disagreement in (22)-(23) is precisely the question of what one ought to count as a publication. To put it differently, the concept of a publication that Abelard and Eloise share does not yet determine by itself whether an online conference working paper should or shouldn't fall in its extension. It is what we might call an open-ended concept, and there is a practical issue of deciding whether or not to extend it in such a way as to include among its instances a certain kind of "new" objects (viz. online working papers). Abelard's judgment in (22) is, indirectly, a proposal to extend that concept in such a way that it will include online working papers, while Eloise in (23) puts forward a proposal in the opposite direction. 
My suggestion, then, is that we view the cases of what looks like an intractable disagreement over matters of evaluative character, including matters of taste and of emotional value, as cases of practical disagreement over the issue of how to construe and apply the concept itself of a given value. To some, this may look like a sheer case of metalinguistic disagreement. ${ }^{12}$ However, although I do not deny that there may be a metalinguistic component involved, what matters is the fairly striking difference with other cases of metalinguistic disagreement, where the two parties get into a dispute simply because they happen to attach different meanings to the words used as would be, to take an extreme case, a dispute over the question whether Joshua lives near a bank, in which the one party intends to be talking about a river bank, and the other, about a financial institution.

More interestingly, we can ask ourselves whether the disagreements in (20)-(21) and in (22)-(23) are faultless. If we accept the idea of an open-ended concept, then indeed, to the extent that at the time of the disagreement, the concept's precise extension is not yet fully determined, neither of the parties will be strictly speaking wrong. In terms of the quadrilemma that we started with in Sect. I, it is assumption $c$, which holds that both statements have a truth value, that we might end up dropping.

12 Indeed, that is the line defended e.g. in Sundell (2011). 
But the crucial point is that, although at the time of dispute, the concept may be open-ended, and the two statements may consequently lack truth values, the way in which the concept and the use of the corresponding term develop will make it possible to decide, albeit retrospectively, which of the two parties got it right. ${ }^{13}$

\section{Acknowledgments}

I would like to thank Stéphane Lemaire for his invitation to the conference on Values and value-judgments in Rennes in May 2010, where I presented an earlier version of the paper, and for editing this special issue. I have benefited from questions and comments from audiences at that conference, as well as at various events at which I presented material from this paper; in particular, the $3^{\text {rd }}$ Language, Context and Cognition Workshop in Valparaiso in August 2010, the $2^{\text {nd }}$ Conference in Philosophy and Linguistics in Belo Horizonte in November 2011, and the PETAF Midterm Conference in Aberdeen in December 2011. Last but not least, let me acknowledge participation and partial funding from the following projects: "Context, Content and Compositionality", European Community's Seventh Framework Programme (FP7/2007-2013), grant $n^{\circ} 229$ 441-CCC; "Perspectival Thoughts and Facts" (PETAF), EC-FP7/2007-2013, grant $\mathrm{n}^{\circ} 238$ 128; and "Semantic Content and Context-Dependence", MICINN, Spanish Government, grant n CSD2009-0056;

13 Of course, in some cases the disagreement over the possible applications of a concept may well result in there coming to be two or more distinct concepts, depending on whether they apply or not to the instances under dispute. 


\section{References}

Egan, Andy, John Hawthorne and Brian Weatherson. 2005. Epistemic modals in context. Contextualism in Philosophy, ed. by G. Preyer and G. Peter. OUP. 131-168. Kölbel, Max. 2002. Truth without objectivity. Routledge.

Lasersohn, Peter. 2005. Context dependence, disagreement, and predicates of personal taste. Linguistics and Philosophy 28. 643-686.

López de Sa, Dan. 2008. Presupposition of Commonality: An Indexical Relativist Account of Disagreement. Relative truth, ed. by Max Kölbel and Manuel GarcíaCarpintero. Oxford: Oxford University Press. 297-310.

MacFarlane, John. 2012. Assessment Sensitivity: Relative Truth and Its Applications. UC Berkeley, manuscript available online.

Richard, Mark. 2008. When truth gives out. Oxford: Oxford University Press.

Sosa, Ernest. 2010. The Epistemology of Disagreement. In Haddock, A. et al. (eds.) Social Epistemology. Oxford: Oxford University Press.

Stephenson, Tamina. 2007. Judge dependence, epistemic modals, and predicates of personal taste. Linguistics and Philosophy 30: 487-525.

Stojanovic, Isidora. 2007. Talking about taste: disagreement, implicit arguments, and relative truth. Linguistics and Philosophy 30: 691-706.

2008. What is said: an inquiry into reference, meaning and content. VDM Verlag.

_ 2011. When (True) Disagreement Gives Out. Croatian Journal of Philosophy 32: 181-193.

2012. Domain-sensitivity. Synthese 184: 137-155.

Sundell, Timothy. 2011. Disagreements About Taste. Philosophical Studies 155: 267 288 . 